\title{
Synovial fluid uric acid level aids diagnosis of gout
}

\author{
BINIT VAIDYA $^{1}$, MANISHA BHOCHHIBHOYA ${ }^{1}$ and SHWETA NAKARMI ${ }^{2}$ \\ ${ }^{1}$ Department of Rheumatology, National Center for Rheumatic Diseases, Kathmandu 44600, Nepal; \\ ${ }^{2}$ Department of Rheumatology, Bangabandhu Sheikh Mujib Medical University, Shahbag, Dhaka-1000, Bangladesh
}

Received November 30, 2017; Accepted May 3, 2018

DOI: $10.3892 /$ br.2018.1097

\begin{abstract}
Examination of urate crystal in synovial fluid (SF) remains the gold standard for diagnosis of gout, but is not universally available. SF uric acid (UA) level may be measured by the uricase method with an automated analyzer. The present study aimed to evaluate the utility of SF to serum UA ratio (SSR) for diagnosis of gout. A cross-sectional study was conducted at the National Center for Rheumatic Diseases, Nepal. Patients presenting with acute ( $<1$ day) joint pain and/or swelling were included. Aspiration was performed in all patients and fluid was subjected to testing for urate level, $\mathrm{pH}$ and cell counts and microscopy. Serum samples were also assessed for urate levels, and the SSR was calculated for each patient. A receiver operating characteristic curve was plotted to determine the cutoff value for indicating diagnosis of gout. The difference in SSR between gout and non-gout effusion was evaluated by one-way analysis of variance. A total of 181 patients were included of which 77 had gout. The remaining cases included osteoarthritis, pseudogout, rheumatoid arthritis and ankylosing spondylitis. SSR was significantly higher in gout patients than in any other group $(\mathrm{P}<0.05)$. An SSR of $\geq 1.01$ had the highest sensitivity and specificity at 89.6 and $66.3 \%$, respectively, for identifying gout effusion. The present results indicated that SSR may be used as an aid for gout diagnosis when polarizing microscopy is not available.
\end{abstract}

\section{Introduction}

Gout is among the most common inflammatory arthritides, characterized by deposition of monosodium urate (MSU) crystals in and around the joint and soft tissue (1-3). Persistent hyperuricemia is an important factor in the development of gout, but not all hyperuricemic patients develop gouty arthritis (4). The risk of supersaturation and crystal formation increases with increasing urate concentration. Alteration in

Correspondence to: Dr Binit Vaidya, Head, Department of Rheumatology, National Center for Rheumatic Diseases, Pashupati Marg, Ratopul, Kathmandu 44600, Nepal

E-mail: drbinitvaidya@yahoo.com

Key words: gout, synovial fluid, uric acid various factors including $\mathrm{pH}$ and temperature also aggravates crystal formation and deposition in joints such as the first metatarsophalangeal (MTP) joint, a normally lower-temperature joint (5). The release of these preformed crystals initiates an intense inflammatory response in the synovium causing acute gouty arthritis (6).

Worldwide prevalence of gout ranges from 0.1 to $10 \%$, with an incidence of 0.3 to 6 cases per 1,000 person-years (7). However, Asian countries including India (8), Bangladesh (9) and Pakistan (10) have been reported as having low gout prevalence, with prevalence rates below $0.5 \%$ according to data published by the Community Oriented Programme for Control of Rheumatic Diseases (7).

Gout typically presents in middle-aged men as severe pain and/or swelling with redness around joints, which may last from hours to days. Acute gouty arthritis usually has monoarticular presentation with a predisposition to develop in joints of lower extremities, particularly the first MTP joint. Other joints including the ankle and wrist may also be affected. Oligo- or polyarticular presentation may also occur, albeit rarely, typically in conditions such as chronic untreated gout or in postmenopausal women (11).

The gold standard test for the diagnosis of gout remains to be identification of MSU crystals in the synovial fluid (SF) by polarizing microscopy (12-14), which has previously been reported to have a sensitivity of at least $84.4 \%$ (15) and specificity of $97.2 \%$ (16). This technique requires specialized equipment and training, and is not available freely in countries with limited resources. Although hyperuricemia is a feature of gout, serum uric acid (UA) level may be within normal range during an acute attack (11). Such normouricemia at the time of an acute attack may be attributed to release of interleukin 6 (IL-6) during the acute inflammatory process (17). UA levels may be efficiently measured in the SF by colorimetric and enzymatic methods. The enzymatic method of UA measurement results from oxidation of UA by the uricase enzyme (18). The present study used the latter method with the aim of evaluating the utility of SF to serum UA ratio (SSR) for diagnosis of gout.

\section{Materials and methods}

Study design. The current study followed a cross-sectional design and was conducted at the rheumatology outpatient clinic of the National Center for Rheumatic Diseases (NCRD) from June 2013 to September 2016. Informed written consent 
was obtained from all patients prior to enrollment in the study or performing aspiration of joint fluid. The study protocol was approved by the ethical review board of the NCRD.

Study population. The study population comprised all patients presenting with joint pain at the NCRD. The sample size was calculated using the worldwide prevalence of gout of $1.7 \%$ (7), a $95 \%$ confidence interval and an $80 \%$ power of the study. Though the calculated sample size was 106 , 181 patients were included in the study as the patient pool was adequate. The inclusion criteria were as follows: Patients with pain and swelling in one or multiple joints of acute onset ( $\leq 1$ day). The exclusion criteria were as follows: i) Patients with chronic joint pain (>14 days); ii) diagnosed cases of rheumatoid arthritis (RA), spondyloarthritis, or gout on treatment with disease-modifying anti-rheumatic drugs or urate lowering therapy; iii) those not willing to give consent for the study protocol. Gout was diagnosed on the basis of American College of Rheumatology/European League Against Rheumatism (ACR/EULAR) 2015 classification criteria (19). RA was diagnosed on the basis of the ACR/EULAR 2010 criteria (20). Spondyloarthritis was diagnosed using the Assessment of Spondyloarthritis International Society classification criteria (21), and ankylosing spondylitis (AS) on the basis of modified New York criteria (22). Osteoarthritis (OA) was diagnosed on the basis of X-ray findings of reduced medial joint space in the absence of chondrocalcinosis with or without apatite crystals in the SF. Pseudogout was diagnosed if there was detection of chondrocalcinosis by X-ray or calcium pyrophosphate dihydrate crystals on SF examination.

Sample collection and analysis. At least $1 \mathrm{ml}$ of SF was aspirated from any swollen joint, which included the first MTP, ankle, knee, wrist and metacarpophalangeal joints. SF aspiration was performed with a heparinized syringe in all patients and the fluid was sent for assessment of UA level, crystallization, $\mathrm{pH}$, cell counts and gram staining at the NCRD. Additionally, serum samples were assessed for UA levels. Serum and SF UA levels were measured by the enzymatic uricase method using an automated analyzer (Erba XL 200; Erba Diagnostics, Mannheim, Germany). The sample collection and microcrystal examination were performed by a standard method as in a previous study by Montagna et al (23). The analyses of SF cell count and gram staining and culture were performed as described by Brannan and Jerrard (24). However, crystal count was not determined. The SSR was calculated for each patient.

Statistical analysis. Statistical tests were performed using SPSS version 17.0 (SPSS, Inc., Chicago, IL, USA). Data were expressed as the mean \pm standard deviation unless otherwise stated. The difference in SSR ratio between gout and non-gout effusions was calculated using one-way analysis of variance followed by Bonferroni's post hoc tests for multiple comparisons. A receiver operating characteristic (ROC) curve was plotted to calculate the cutoff value of SSR ratio for the diagnosis of gout. Internal validation was performed using bootstrapping. $\mathrm{P}<0.05$ was considered to indicate a statistically significant difference.

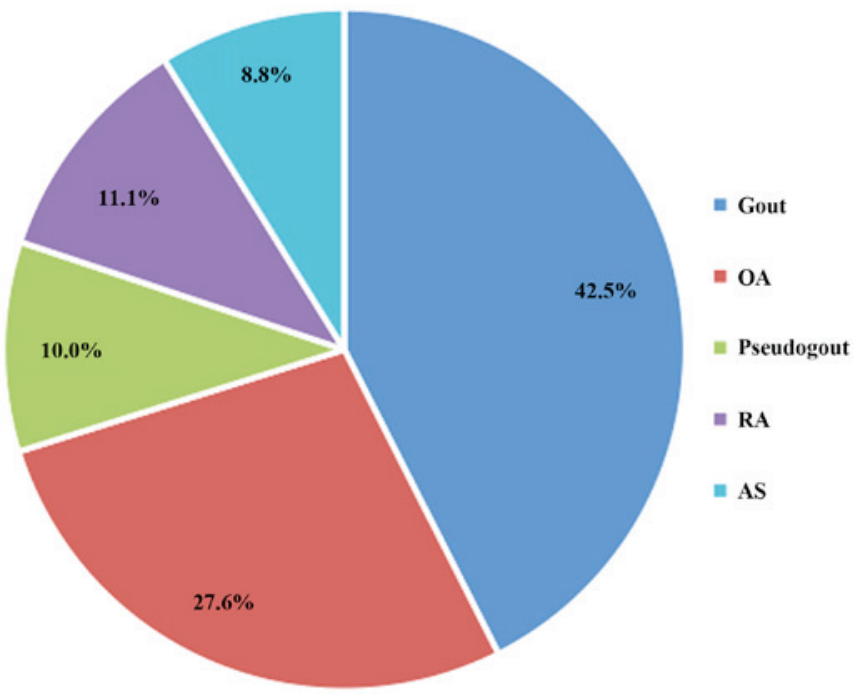

Figure 1. Frequencies of diagnoses. OA, osteoarthritis; RA, rheumatoid arthritis; AS, ankylosing spondylitis.

\section{Results}

Clinicodemographic profile. A total of 181 patients who presented with acute joint pain and/or swelling were included. The mean age of patients was $51.5 \pm 9.6$ years, and $79 \%$ were males. The overall male: female ratio was 3.7:1. Gout was diagnosed in $77(42.5 \%)$ of patients. The frequencies of other diagnoses are presented in Fig. 1.

The differences in age, gender, and SF and serum urate levels of patients with each diagnosis are presented in Table I.

SSR. The SF UA level was significantly higher in patients with gout when compared with that in patients with pseudogout $(\mathrm{P}=0.001)$ or AS $(\mathrm{P}<0.001$; Table I). SSR was significantly higher in gout patients than in patients with $\mathrm{OA}(\mathrm{P}<0.001)$, pseudogout $(\mathrm{P}=0.013)$, RA $(\mathrm{P}<0.001)$ or AS $(\mathrm{P}<0.001$; Table II). When comparing SSR between groups excluding gout, no significant differences were determined (Table II). Serum UA level did not differ significantly between the groups except between RA and pseudogout ( $\mathrm{P}=0.015$; Table I).

A ROC curve was plotted for SSR (Fig. 2). An SSR of $\geq 1.01$ was associated with the highest sensitivity and specificity, at 89.6 and $66.3 \%$, respectively, for diagnosis of gout. The area under the curve was 0.82 . The higher the value of SSR above 1.01 , the greater the specificity for diagnosis of gout.

\section{Discussion}

SF may be considered as a dialysate of blood plasma (25). As small molecules including urate pass freely through the double barrier of the synovial membrane into SF, the concentration of most non-electrolytes and micromolecules in SF is similar to that of plasma $(26,27)$ except for the few macromolecules that are secreted by the synovial membrane and surrounding tissues (28). Most non-electrolytes diffuse freely between serum and SF, while electrolytes follow the Gibbs-Donnan equilibrium. UA is filtered from plasma to $\mathrm{SF}$, and the normal SF urate level is equal to or slightly lower than the serum levels (29). There are different hypotheses 
Table I. Comparison of urate levels between groups.

\begin{tabular}{|c|c|c|c|c|c|c|}
\hline \multirow[b]{2}{*}{ Variable } & \multicolumn{6}{|c|}{ Diagnosis } \\
\hline & $\begin{array}{l}\text { Gout } \\
(\mathrm{n}=77)\end{array}$ & $\begin{array}{c}\mathrm{OA} \\
(\mathrm{n}=50)\end{array}$ & $\begin{array}{l}\text { Pseudogout } \\
\qquad(\mathrm{n}=18)\end{array}$ & $\begin{array}{c}\mathrm{RA} \\
(\mathrm{n}=20)\end{array}$ & $\begin{array}{c}\text { AS } \\
(\mathrm{n}=16)\end{array}$ & P-value \\
\hline Age, years & $49.0 \pm 10.0$ & $54.6 \pm 9.8$ & $50.9 \pm 8.6$ & $53.0 \pm 10.2$ & $51.9 \pm 3.8$ & \\
\hline Serum UA & $6.2 \pm 0.8$ & $6.3 \pm 0.7$ & $5.8 \pm 0.8^{\mathrm{a}}$ & $6.7 \pm 0.5^{\mathrm{a}}$ & $6.0 \pm 0.9$ & 0.019 \\
\hline Synovial UA & $6.6 \pm 0.8 b^{c}$ & $6.1 \pm 0.9$ & $5.7 \pm 0.9^{b}$ & $6.3 \pm 0.9$ & $5.5 \pm 0.9^{c}$ & $<0.001$ \\
\hline $\begin{array}{l}\text { Synovial fluid to } \\
\text { serum UA ratio }\end{array}$ & $1.1 \pm 0.1$ & $1.0 \pm 0.1$ & $1.0 \pm 0.1$ & $0.9 \pm 0.1$ & $0.9 \pm 0.1$ & $<0.001$ \\
\hline $\mathrm{SF}$ pH & $7.4 \pm 0.0$ & $7.4 \pm 0.1$ & $7.4 \pm 0.0$ & $7.4 \pm 0.0$ & $7.4 \pm 0.0$ & 0.800 \\
\hline $\begin{array}{l}\text { SF total cell } \\
\text { count/cumm, } \\
\text { median (range) }\end{array}$ & $\begin{array}{c}9,300 \\
(1,000-18,000)\end{array}$ & $\begin{array}{c}3,000 \\
(800-10,000)\end{array}$ & $\begin{array}{c}10,200 \\
(2,000-22,000)\end{array}$ & $\begin{array}{c}8,500 \\
(3,000-30,000)\end{array}$ & $\begin{array}{c}6,700 \\
(2,700-16,000)\end{array}$ & 0.720 \\
\hline SF gram stain & All negative & All negative & All negative & All negative & All negative & - \\
\hline
\end{tabular}

Values are presented as the mean \pm standard deviation unless otherwise stated. Values with alike superscript letters were significantly different (determined by Bonferroni's post hoc tests); ${ }^{\mathrm{a}} \mathrm{P}=0.015,{ }^{\mathrm{b}} \mathrm{P}=0.001,{ }^{\mathrm{C}} \mathrm{P}<0.001$. UA, uric acid; OA, osteoarthritis; RA, rheumatoid arthritis; AS, ankylosing spondylitis.

Table II. Comparison of SSR between different study groups.

\begin{tabular}{lrr}
\hline Diagnosis (SSR) & P-value \\
\hline Gout $(1.06 \pm 0.07)$ & OA $(0.96 \pm 0.08)$ & $<0.001$ \\
& Pseudogout $(0.98 \pm 0.09)$ & 0.013 \\
& RA $(0.94 \pm 0.11)$ & $<0.001$ \\
AS $(0.92 \pm 0.14)$ & $<0.001$ \\
OA $(0.96 \pm 0.08)$ & Pseudogout $(0.98 \pm 0.09)$ & 1.000 \\
& RA $(0.94 \pm 0.11)$ & 1.000 \\
& AS $(0.92 \pm 0.14)$ & 1.000 \\
\hline
\end{tabular}

SSR, synovial fluid to serum uric acid ratio; OA, osteoarthritis; RA, rheumatoid arthritis; AS, ankylosing spondylitis.

regarding the distribution of urate in serum and SF. According to Beutler et al (30), the concentration of UA in SF is identical to that in the blood. However, previous study has demonstrated that SF urate levels were higher than serum levels in patients with acute gouty attack (31). During the acute attack of gout, approximately $40 \%$ of patients may be normouricemic which may be attributed to various factors including long-term excessive alcohol intake, diuretic therapy, obesity, release of IL-6 and use of urate lowering therapy, among others (32). Thus, the current study selected the ratio of SF urate to serum urate as a measure to verify higher UA concentration in the SF of patients with gout.

In the present study, the percentage of patients with gout was higher in comparison with those of other inflammatory and non-inflammatory arthritides. This may be because of the criteria of acute onset joint pain and/or swelling. This may also explain the higher percentage of male patients. It was identified that an SSR of $\geq 1.01$ was significantly associated with diagnosis of gout determined through MSU crystal examination

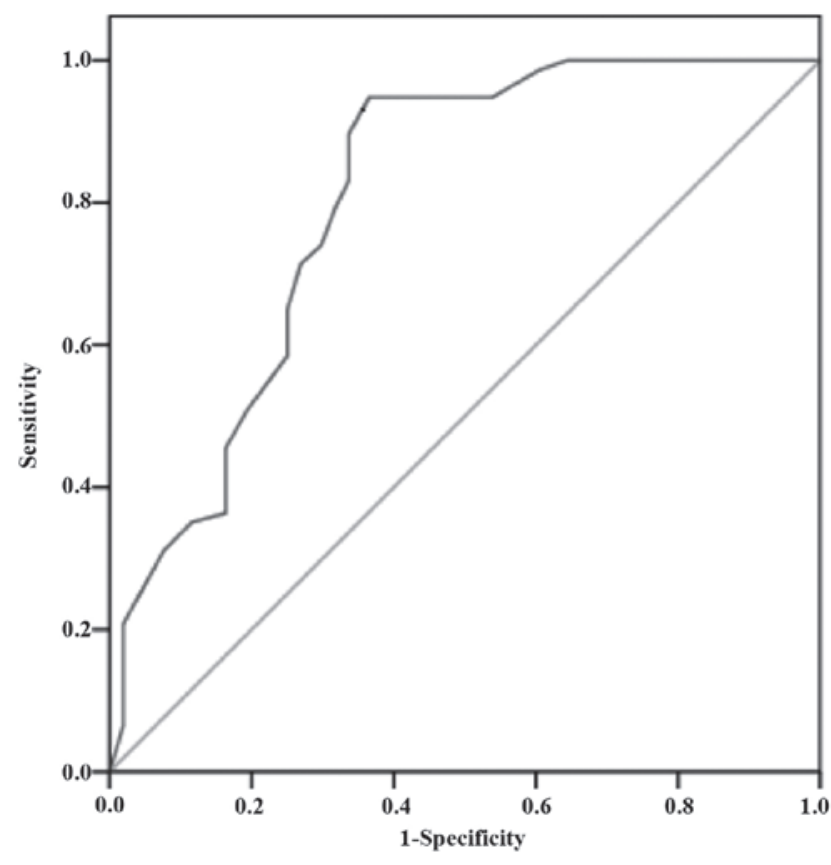

Figure 2. ROC curve for the diagnostic value of synovial fluid to serum uric acid ratio. Diagonal segments are produced by ties. The curved line represents the ROC curve; the straight line represents the intercept at $45^{\circ}$. A synovial fluid to serum uric acid ratio of 1.01 was associated with the highest sensitivity and specificity at 89.6 and $66.3 \%$, respectively. ROC, receiver operating characteristic.

by polarizing microscopy. Values $<1.01$ were associated with non-gout effusions including those of pseudogout or OA cases. These findings are consistent with the hypothesis that a higher level of UA in SF may in part mediate gout onset. However, there are multiple factors that may be involved in gout onset, including $\mathrm{pH}$ (MSU crystal solubility increases with increasing $\mathrm{pH}$ to a maximum at $\mathrm{pH} 7.7$ at $37^{\circ} \mathrm{C}$ ), osmolality, and serum-SF gradients of calcium, phosphorus, albumin and globulin (32). 
A study in 1965 observed a similar finding of higher SF urate level in patients with gout when compared with those with knee swelling due to other causes (31). However, their data was limited to 27 patients and lacked calculation of the predictive ratio for diagnosis of gout. The present study elaborated on this by obtaining more samples, and determined the predictive value of SSR to be $\geq 1.01$ with $89.6 \%$ sensitivity.

Consistent with the findings of the current study, Wangkaew et al (33) demonstrated that SF urate and SSR were significantly different in patients with gout compared within other types of arthritis. However, in their study, the serum UA levels were also higher in gout patients. By contrast the present data indicated that serum UA as an independent marker may not be reliable for identification of gouty arthritis.

Beutler et al (30) reported that SF urate levels tended to reflect serum levels in patients with gout and non-inflammatory arthropathies but not with inflammatory joint disorders. The results of their study did not explain the higher level of SFUA in non-inflammatory arthritis, and contradict the present data. This may be due to the small sample size in their study and selection differences of the study population. Nonetheless, the results of the current study may aid to clarify the relationship between synovial and serum UA levels in gout and non-gout populations in a larger group of patients. The results also indicate a cutoff value for SSR in predicting gout as a cause of joint pain and swelling when the gold standard test for diagnosis is not available. Notably, the higher the SSR value, the more specific it was indicated to be for identifying gout-associated effusion. An external validation of the data with larger groups is now required for confirmation of these findings.

In conclusion, though identification of MSU crystals by polarized microscopy is the gold standard method for the diagnosis of gout, some laboratories and diagnostic centers lack this facility. It also requires a qualified and experienced technician. In this context, measurement of SF urate level may be used as an alternative method, as it is inexpensive, does not require special training or equipment and may be performed in regions where technologically advanced laboratories and equipment may not be available. It may also be effective in differentiating gout effusions from others when there is diagnostic uncertainty. Thus, measurement of SF urate level may be used as an alternative test for diagnosis of gout when polarized microscopy is not available.

\section{Acknowledgements}

The authors are thankful to Dr Renu Shrestha (Consultant Pathologist, NCRD, Ratopul, Kathmandu, Nepal) and Mr. Ravi Prajapati (Senior Technician, NCRD) for their technical assistance.

\section{Funding}

No funding was received.

\section{Availability of data and materials}

The datasets used and/or analyzed during the current study are available from the corresponding author on reasonable request.

\section{Authors' contributions}

BV conceived the study and was responsible for data analysis and drafting of the manuscript. MB was responsible for data collection and reviewing the literature. SN was responsible for data analysis and drafting of the manuscript. All authors read and approved the final version.

\section{Ethics approval and consent to participate}

The study protocol was approved by the ethical review board of the NCRD. Informed written consent was obtained from all participants prior to enrollment.

\section{Consent for publication}

Consent for publication of relevant data was obtained from patients following anonymization of personal information.

\section{Competing interests}

The authors declare that they have no competing interests.

\section{References}

1. So A: Gout in the spotlight. Arthritis Res Ther 10: 112, 2008.

2. Martinon F and Glimcher LH: Gout: New insights into an old disease. J Clin Invest 116: 2073-2075, 2006.

3. Currie WJ: The gout patient in general practice. Rheumatol Rehabil 17: 205-217, 1978

4. Campion EW, Glynn RJ and DeLabry LO: Asymptomatic hyperuricemia. Risks and consequences in the Normative Aging Study. Am J Med 82: 421-426, 1987.

5. Choi HK, Mount DB and Reginato AM; American College of Physicians; American Physiological Society: Pathogenesis of gout. Ann Intern Med 143: 499-516, 2005.

6. McCarty DJ Jr, Phelps P and Pyenson J: Crystal-induced inflammation in canine joints. I. An experimental model with quantification of the host response. J Exp Med 124: 99-114, 1966.

7. Kuo CF, Grainge MJ, Zhang W and Doherty M: Global epidemiology of gout: Prevalence, incidence and risk factors. Nat Rev Rheumatol 11: 649-662, 2015.

8. Chopra A, Patil J, Billempelly V, Relwani J and Tandle HS; WHO-ILAR COPCORD Study. WHO International League of Associations from Rheumatology Community Oriented Program from Control of Rheumatic Diseases: Prevalence of rheumatic diseases in a rural population in western India: A WHO-ILAR COPCORD Study. J Assoc Physicians India 49: 240-246, 2001.

9. Haq SA, Darmawan J, Islam MN, Uddin MZ, Das BB, Rahman F, Chowdhury MA, Alam MN, Mahmud TA, Chowdhury MR, et al: Prevalence of rheumatic diseases and associated outcomes in rural and urban communities in Bangladesh: A COPCORD study. J Rheumatol 32: 348-353, 2005.

10. Farooqi A and Gibson T: Prevalence of the major rheumatic disorders in the adult population of north Pakistan. Br J Rheumatol 37: 491-495, 1998.

11. Ragab G, Elshahaly M and Bardin T: Gout: An old disease in new perspective - A review. J Adv Res 8: 495-511, 2017.

12. Hainer BL, Matheson E and Wilkes RT: Diagnosis, treatment, and prevention of gout. Am Fam Physician 90: 831-836, 2014.

13. Beutler A and Schumacher HR Jr: Gout and 'pseudogout'. When are arthritic symptoms caused by crystal deposition? Postgrad Med 95: 103-106, 109, 113-116 passim, 1994.

14. Schlesinger N: Diagnosis of gout. Minerva Med 98: 759-767, 2007.

15. Wallace SL, Robinson H, Masi AT, Decker JL, McCarty DJ and Yü TF: Preliminary criteria for the classification of the acute arthritis of primary gout. Arthritis Rheum 20: 895-900, 1977.

16. Chen LX and Schumacher HR: Current trends in crystal identification. Curr Opin Rheumatol 18: 171-173, 2006.

17. Tsutani $\mathrm{H}$, Yoshio $\mathrm{N}$ and Ueda T: Interleukin 6 reduces serum urate concentrations. J Rheumatol 27: 554, 2000. 
18. Barr WG: Uric Acid. In: Clinical Methods: The History, Physical, and Laboratory Examinations. Walker HK, Hall WD and Hurst JW (eds). 3rd edition. Butterworths, Boston, 1990.

19. Neogi T, Jansen TL, Dalbeth N, Fransen J, Schumacher HR, Berendsen D, Brown M, Choi H, Edwards NL, Janssens HJ, et al: 2015 Gout classification criteria: An American College of Rheumatology/European League Against Rheumatism collaborative initiative. Ann Rheum Dis 74: 1789-1798, 2015.

20. Aletaha D, Neogi T, Silman AJ, Funovits J, Felson DT, Bingham CO III, Birnbaum NS, Burmester GR, Bykerk VP, Cohen MD, et al: 2010 Rheumatoid arthritis classification criteria: An American College of Rheumatology/European League Against Rheumatism collaborative initiative. Arthritis Rheum 62 : 2569-2581, 2010.

21. Rudwaleit M, van der Heijde D, Landewé R, Akkoc N, Brandt J, Chou CT, Dougados M, Huang F, Gu J, Kirazli Y, et al: The Assessment of SpondyloArthritis International Society classification criteria for peripheral spondyloarthritis and for spondyloarthritis in general. Ann Rheum Dis 70: 25-31, 2011.

22. van der Linden S, Valkenburg HA and Cats A: Evaluation of diagnostic criteria for ankylosing spondylitis. A proposal for modification of the New York criteria. Arthritis Rheum 27: 361-368, 1984.

23. Montagna P, Brizzolara R, Ferrone C, Cutolo M, Paolino S and Cimmino MA: A method for counting monosodium urate crystals in synovial fluid. Reumatismo 67: 29-32, 2015.

24. Brannan SR and Jerrard DA: Synovial fluid analysis. J Emerg Med 30: 331-339, 2006

25. Gatter RA and Schumacher HR: A Practical Handbook of Joint Fluid Analysis. 2nd edition. Lea \& Febiger, Philadelphia, PA, 1991.
26. Schmid K and MacNair MB: Characterization of the proteins of certain postmortem human synovial fluids. J Clin Invest 37: 708-718, 1958.

27. Schmid K and MacNair MB: Characterization of the proteins of human synovial fluid in certain disease states. J Clin Invest 35: 814-824, 1956

28. Ruiz-Romero C, Calamia V, Carreira V, Mateos J, Fernández P and Blanco FJ: Strategies to optimize two-dimensional gel electrophoresis analysis of the human joint proteome. Talanta 80: 1552-1560, 2010.

29. Ropes MW, Bennett GA and Bauer W: The Origin and Nature of Normal Synovial Fluid. J Clin Invest 18: 351-372, 1939.

30. Beutler AM, Keenan GF, Soloway S, Norden D, Luchi M and Schumacher HR Jr: Soluble urate in sera and synovial fluids from patients with different joint disorders. Clin Exp Rheumatol 14: 249-254, 1996.

31. Reeves B: Significance of joint fluid uric acid levels in gout. Ann Rheum Dis 24: 569-571, 1965

32. Rozin AP, Braun-Moscovici Y and Balbir-Gurman A: Serum-synovial gradient data of normouricemic patients with history of gout and acute knee effusion. Clin Rheumatol 25: 886-888, 2006.

33. Wangkaew S, Kasitanon N, Hongsongkiat S, Tanasombat C, Sukittawut W and Louthrenoo W: A comparative study of serum and synovial fluid levels of uric acid between patients with gout and other arthritides. J Med Assoc Thai 97: 679-685, 2014. 